\title{
Stability Analyses and Heritability of a Doubled Haploid Population of Barley (Hordeum vulgare L.)
}

\author{
Mohamed B. Ali ${ }^{\#}$ Mohammed A. Sayed \\ Agronomy Department, Faculty of Agriculture, Assiut University, Assiut, Egypt.
}

\begin{abstract}
A SSESSMENT of genotype-by-environment interaction $(\mathrm{G} \times \mathrm{E})$ is a curial step in any breeding program through multi-environmental trials (MET). In the current study, we grow a bi-parental population consists of $297 \mathrm{BC} 2 \mathrm{DH}$ lines along with their parents and a local check cultivar in four locations for two years (2016/2017 and 2017/2018) across Egypt. We employed different statistical analyses including AMMI, Eberhart and Russell and Tai's analyses to assess the $\mathrm{G} \times \mathrm{E}$. In addition, we estimated broad-sense heritability for grain yield per plant as well as phenotypic and genotypic coefficient of variation. We found that environment $(E)$, genotype $(G)$ and $\mathrm{G} \times \mathrm{E}$ accounted for $52.52,10.61$ and $36.87 \%$ of sums of squares of treatment, respectively. Some DHs, e.g. 19, 65 and 4 were stable and adapted across environments unlike 73, 9 and 95, which were not stable across all environments but specifically adapted to Nubaria location during the two growing seasons. Both similar and dissimilar results found using Eberhart and Russel and Tai's analyses. However, the AMMI biplot analysis successfully elucidate the which-won-where pattern. For the heritability estimates, we found that grain yield per plant showed moderate heritability estimate $(0.50)$. This indicated that this trait can be improved under investigated environments. We identified some promising stable DHs lines that might be used in barley breeding programs in Egypt. Some of these DHs performed better than both parents and the local check cultivar.
\end{abstract}

Keywords: Additive main effects and multiplicative interaction, Stability, Ebertahrt and Russell, Tai, Variance components, Biplot analysis.

\section{Introduction}

Barley (Hordeum vulgare L.) is one of the leading cereal crops of the world and has been considered as an important crop in human diets worldwide. Beside this, barley has the advantage, it has also been used virtually worldwide as a model species for biological research. It is a diploid species with a low chromosome number $(2 \mathrm{n}=14)$ possessing large chromosomes, and hence, a large genome (Von Bothmer et al., 2003).

Multi-environmental trials (MET) are essential in any breeding programs to ensure stability of traits of interest for all crops. In MET, genotype $\times$ environment interaction $(\mathrm{G} \times \mathrm{E})$ is detected when the performance of genotypes fluctuates across diverse environments. Thus, plant breeders are required to assess stability genotypes for traits of interest, e.g. yield, over diverse environments including years and locations as an initial step prior releasing new breeding germplasms. Numerous statistical methods have assessed the $\mathrm{G} \times \mathrm{E}$ by plant breeders in order to identify stable genotypes. These methods can be categorized either as univariate (parametric or nonparametric), e.g. Eberhart and Russell model, or multivariate models, e.g. AMMI model.

Eberhart \& Russell (1966) provided plant breeders with a model to assess parametric stability measures precisely based on mean, coefficient of regression and deviation from regression. This model is widely used by plant breeder, however, the violation of certain assumption of this model, i.e. linear response of germplasm to diverse environments, using huge number of genotypes, may mislead plant breeder to wrong decision about the stability of genotypes (Flores et al., 1998). This model enables plant breeders to identify

\#Corresponding author email: mali@aun.edu.eg 
stable genotypes, but it does not provide any information about which-won-where pattern across environments.

Tai (1971) showed that a lamba-value $\left(\lambda_{\mathrm{i}}\right)$ can be employed to estimate the yield stability of genotypes, as $\lambda_{\mathrm{I}}$ less than 1 designate the deviation from the regression models are small.

Phenotypic yield stability in agronomic sense can be measured by deviations from regression ( $\lambda$ ) (Tai, 1971).

The additive main effects and multiplicative interaction (AMMI) is an extensively used and most known statistical model for assessing $\mathrm{G} \times \mathrm{E}$ (Zobel et al., 1988 and Gauch, 1992). It is hypothesized on singular value decomposition and uses graphical display of biplot analysis to identify which-won-where pattern (Gauch et al., 2008). In addition, it can be exploited to comprehend the structure of $\mathrm{G} \times \mathrm{E}$ (Hongyu et al., 2014). Hongyu et al. (2014) stated the two major objectives of AMMI analysis as the following: (1) Elucidating the $\mathrm{G} \times \mathrm{E}$, which comprises describing mega-environments and identifying the superior genotypes, and (2) Maximizing precision to improve recommendations, heritability and selections. The biplot graphical display, which is a scatter plot of genotypes and their principal component scores, allows the plant breeders to identify stable genotypes. The presence of significant $\mathrm{G} \times \mathrm{E}$ constrains plant breeders work of selecting genotypes with good performance and stability (Kang \& Pham, 1991).

Heritability's estimate can play an important role in the trustworthiness of phenotyping (Arulbalachandran et al., 2010). In addition, it indicates the importance of estimating heritability for plant breeders as it determines the chance and amount of possible improvement via different selection procedures (Addisu \& Shumet, 2015). Therefore, high heritability value for a trait of interest can facilitate the plant breeder to make the appropriate selection (Unche et al., 2008). Several studies classified broad-sense heritability into three categories as low, medium and high (Johnson et al., 1955; Robinson, 1966 and Addisu \& Shumet, 2015).

The current study aimed to assess the stability and heritability of a double haploid population of barely across Egypt.

\section{Materials and Methods}

Plant material

An advanced backcross doubled haploid population of covered two rows barley designated as S42 and consisted of 297 BC2DH lines (DH) derived from crossing between a German elite cultivar of $H$. vulgare ssp. vulgare 'Scarlett' with an exotic accession of $H$. vulgare ssp. spontaneum 'ISR42-8'. The development of the S42 population was according to von Korff et al. (2004). In addition, a covered two rows cultivar of barley, Giza 127 was used in current study as a check cultivar.

\section{Experimental sites and design}

All genotypes were grown at four locations across Egypt (Assiut, Al-Wadi Al-Asiouty, Matrouh and Nubaria) during 2016/2017 and 2017/2018 seasons. All these locations were normally irrigated except Matrouh location that was considered as a rainfed condition. These locations displayed diversified environments in Egypt (Table 1). The experiments were arranged in an incomplete lattice design with three replications and 10 incomplete blocks. Each block contained 10 genotypes. Each genotype was grown in one row $4 \mathrm{~m}$ long, $0.25 \mathrm{~m}$ apart, $0.10 \mathrm{~m}$ inter-plant spacing and one grain per hill to get single plants. The adopted cultural practices for optimum barley production were carried out at each location

\section{Trait studied}

At harvesting, grain yield per plant (GYP; g) were recorded.

\section{Statistical analysis}

The Genotype $\times$ Environment Analysis with $\mathrm{R}$ for Windows, Version 4.0 (GEA-R) (Pacheco et al., 2016) was used to calculate stability parameters (Eberhart \& Russell, 1966) and additive main effects and multiplicative interaction (AMMI) analysis for GYP (g).

Broad-sense heritability for GYP combined across environments were estimated using META-R 5.0 package (Alvarado et al., 2015) as the following:

$$
\mathrm{h}_{\mathrm{b}}^{2}=\frac{\sigma_{\mathrm{g}}^{2}}{\sigma_{\mathrm{G}}^{2}+\sigma_{\mathrm{G} \times \mathrm{E}}^{2} / \mathrm{e}+\sigma_{\mathrm{error}}^{2} / \mathrm{re}}
$$


where $\sigma_{G}^{2}, \sigma_{\mathrm{G} \times \mathrm{E}}^{2}$ and $\sigma_{\text {error }}^{2}$ are the genotype, the genotype by environment interaction and the error variance, respectively, and e and $r$ are the number of environments and replications, respectively.

We used the following formulas of Burton \& Devane (1953) to estimate both genotypic and phenotypic coefficients of variability:

$$
\begin{aligned}
& \operatorname{PCV} \%=\frac{\sqrt{\sigma_{\mathrm{p}}^{2}}}{\overline{\mathrm{x}}} \times 100 \\
& \mathrm{GCV} \%=\frac{\sqrt{\sigma_{\mathrm{g}}^{2}}}{\overline{\mathrm{x}}} \times 100
\end{aligned}
$$

Where, PCV is the phenotypic coefficient of variation, GCV is the genotypic coefficient of variation and $\overline{\mathbf{z}}$ is the grand mean.

Partitioning the $\mathrm{G} \times \mathrm{E}$ interaction effect of $\mathrm{I}^{\text {th }}$ genotype into two Tai's statistics (Tai, 1971), namely $\alpha$ and $\lambda$, which measures linear response to environmental effects and the deviation from linear response, respectively, was done using The Genotype $\times$ Environment Analysis with $\mathrm{R}$ for Windows, Version 4.0 (GEA-R) (Pacheco et al., 2016).

\section{$\underline{\text { Results }}$}

\section{AMMI analysis of variance}

Based on AMMI model and Gollob's F-test (Gollob, 1968) for grain yield per plant (GYP), we found that the genotype $(G)$, environment $(E)$ and genotype-by-environment interaction $(\mathrm{G} \times \mathrm{E})$ exhibited significant differences $(\mathrm{P}<0.001)$ for GYP (g) (Table 2). The portions of sums of squares (SS) attributed to $\mathrm{E}, \mathrm{G}$ and $\mathrm{G} \times \mathrm{E}$ were $52.52 \%, 10.61 \%$ and $36.87 \%$ of the treatment SS, respectively.

The $\mathrm{G} \times \mathrm{E}$ constituent consisted of eight interaction principal component axes (IPCA); however, the first two IPCAs were the most important ones as they explained 62.38 and $24.34 \%$ of the G×E SS, respectively, for GYP (g). The remaining six IPCAs were the least important as they explained $13.28 \%$ of the $\mathrm{G} \times \mathrm{E}$ SS.

TABLE 1. Description of experimental locations.

\begin{tabular}{|c|c|c|c|c|}
\hline \multirow{2}{*}{ Agro-ecological character } & \multirow[b]{2}{*}{ Assiut } & \multirow[b]{2}{*}{ Al-Wadi Al-Asiouty } & \multirow[b]{2}{*}{ Matrouh } & \multirow[b]{2}{*}{ Nubaria } \\
\hline & & & & \\
\hline Latitude & $27.18^{\circ} \mathrm{N}$ & $27.12^{\circ} \mathrm{N}$ & $31.35^{\circ} \mathrm{N}$ & $30.32^{\circ} \mathrm{N}$ \\
\hline Longitude & $31.16^{\circ} \mathrm{E}$ & $32.40^{\circ} \mathrm{E}$ & $27.18^{\circ} \mathrm{E}$ & $30.17^{\circ} \mathrm{E}$ \\
\hline Soil type & Clay & Sandy Loam & Sandy clay loam & Sandy Loam \\
\hline $\begin{array}{l}\text { Annual rainfall }{ }^{\dagger}(\mathrm{mm}) \\
(2016 / 2017)\end{array}$ & $1.00 \mathrm{~mm}$ & $1.00 \mathrm{~mm}$ & $105.50 \mathrm{~mm}$ & $57.00 \mathrm{~mm}$ \\
\hline $\begin{array}{l}\text { Annual rainfall }{ }^{\dagger}(\mathrm{mm}) \\
(2017 / 2018)\end{array}$ & $0.00 \mathrm{~mm}$ & $0.00 \mathrm{~mm}$ & $200.00 \mathrm{~mm}$ & $58.00 \mathrm{~mm}$ \\
\hline $\begin{array}{l}\text { Maximum temperature }{ }^{\ddagger}\left({ }^{\circ} \mathrm{C}\right) \\
(2016 / 2017)\end{array}$ & 25.07 & 27.50 & 21.25 & 22.00 \\
\hline $\begin{array}{l}\text { Minimum temperature }{ }^{\ddagger}\left({ }^{\circ} \mathrm{C}\right) \\
(2016 / 2017)\end{array}$ & 10.81 & 10.90 & 12.44 & 13.04 \\
\hline $\begin{array}{l}\text { Maximum temperature }{ }^{\ddagger}\left({ }^{\circ} \mathrm{C}\right) \\
(2017 / 2018)\end{array}$ & 28.20 & 29.40 & 22.50 & 22.30 \\
\hline $\begin{array}{l}\text { Minimum temperature }\left({ }^{\circ} \mathrm{C}\right) \\
(2017 / 2018)\end{array}$ & 12.30 & 11.70 & 12.60 & 13.40 \\
\hline
\end{tabular}

Locations

${ }^{\dagger}$ Rainfall data were obtained from the Global Summary of the Day (GSOD) dataset of the National Climatic Data Center NNDC (ftp:// ftp.ncdc.noaa.gov/pub/data/gsod/) for the two growing seasons (2016/2017 and 2017/2018).

\$ Average temperature was calculated from the daily temperature data over the two growing seasons. Data were downloaded for the period from the first of October to the end of April (the growing season of the winter crops). 
TABLE 2. Additive main effects and multiplicative interaction (AMMI) analyses of variance for grain yield per plant (g) across eight environments.

\begin{tabular}{lccccc}
\hline Source & DF & SS & $\begin{array}{c}\text { Explained SS } \\
(\%)\end{array}$ & $\begin{array}{c}\text { Explained SS (\%) } \\
\text { accumulated }\end{array}$ & MS \\
\hline Environment (E) & 7 & 45311.95 & 52.52 & 52.52 & $6473.14^{* * *}$ \\
Genotype (G) & 299 & 9151.88 & 10.61 & 63.13 & $30.61^{* * *}$ \\
G×E & 2093 & 31803.77 & 36.87 & 100.00 & $15.20^{* * *}$ \\
$\quad$ PC1 & 305 & 19838.95 & 62.38 & 62.38 & $65.05^{* * *}$ \\
PC2 & 303 & 7742.15 & 24.34 & 86.72 & $25.55^{* * *}$ \\
PC3 & 301 & 1393.78 & 4.38 & 91.11 & $4.63^{* * *}$ \\
PC4 & 299 & 1207.13 & 3.80 & 94.90 & $4.04^{* * *}$ \\
PC5 & 297 & 772.49 & 2.43 & 97.33 & $2.60^{* * *}$ \\
PC6 & 295 & 482.30 & 1.52 & 98.85 & $1.63^{* *}$ \\
PC7 & 293 & 366.97 & 1.15 & 100.00 & 1.25 \\
Residuals & 4800 & 6600.98 & & & 1.38 \\
\hline
\end{tabular}

${ }_{* * * * * *}$ Significant at $\mathrm{P}<0.01$ and $\mathrm{P}<0.001$ probability level, respectively.

Variance components and broad-sense heritability

In the present study, we estimated variance components and broad-sense heritability combined across the eight investigated environments for GYP (Table 3). Briefly, variance components due to $G$ and $G \times E$ were significant $(\mathrm{P}<0.001)$. Furthermore, the variance component due to $\mathrm{G} \times \mathrm{E}$ was larger (4.62) than $\mathrm{G}$ variance $(0.64)$. The broad-sense heritability estimate was $50 \%$. The PCV and GCV \% were $\approx$ 23 and 14, respectively.

TABLE 3. Variance components and heritability (broad sense) combined across environments (locations considered as fixed).

\begin{tabular}{lc}
\hline Statistic & GYP \\
\hline Heritability & 0.50 \\
Genotype variance & $0.64^{* * *}$ \\
Genotype $\times$ Environment variance & $4.62^{* * *}$ \\
Residual variance & 1.31 \\
\hline Grand mean & 5.53 \\
CV $(\%)$ & 20.71 \\
PCV $(\%)$ & 23.00 \\
GCV $(\%)$ & 14.47 \\
\hline
\end{tabular}

${ }^{* * *}$ Significant at $\mathrm{P}<0.001$ probability level.

\section{AMMI1 biplot}

The AMMI1 biplot (Fig. 1) visualized the relationship between mean grain yield per plant (g) and the first interaction principal component (IPC1) effects of both genotypes and environments. Based on the AMMI1 biplot analysis, a number of DHs including, e.g. 19, 65, 4, $264,155,12,43,159$ and 87 were the most widely adapted genotype as they possessed the lowest values of IPC1 and yielded more than mean GYP (5.53 g) (Supplemental Table 1). Furthermore, some DHs, e.g. 73, 9, 95, 113, 100, 193, 147 and 295, were not stable across environments as they possessed high values of IPC1 but they were specifically adapted to both N16 and N17 where they yielded more than mean GYP. In addition, some other DHs, e.g. 17, 6, 41, 34, 11, 5 and 29, were adapted specifically to A16 and yielded more than mean GYP. Moreover, some DHs, e.g. 51, 44, 55, 64, 31, and 60 were adapted specifically to M16 and M17, but yielded less than mean GYP whilst other DHs, e.g. 139, 137, 52 and 84 were adapted to W16, W17 and A17. The check cultivar (Giza127) that is shown in Fig. 1 as 1 yielded more than average GYP but was not stable across environments. This check cultivar was mainly adapted to A16. On the other hand, the wild parent (ISR 42-8) of the DH population yielded about half of the average GYP and was adapted to heat stress environments (W16, W17 and A17). The environment A17 was hit by heat waves during the growing season, which resulted in increasing the average temperature of this season. Further, the other parent (Scarlett) yielded just below the average GYP and was specifically adapted to M16 and M17. 


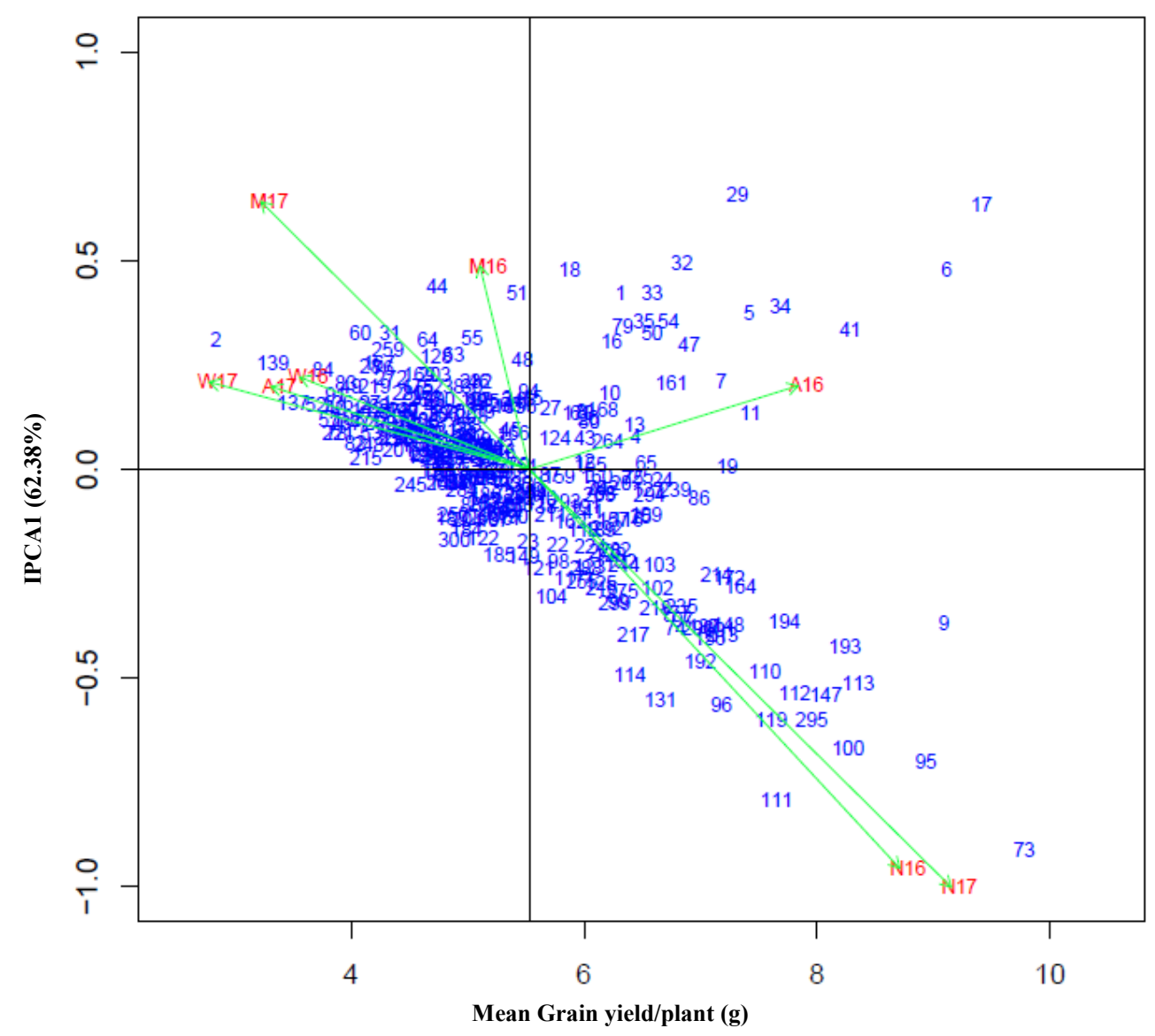

Fig 1. AMMI biplot showing the mean grain yield/plant (g) and the first interaction principal component (IPC1) effects of both genotypes and environments on grain yield/plant. The data represented the doubled haploid population of barley and eight environments (A16= Assiut 2016/2017; A17= Assiut 2017/2018; M16= Matrouh 2016/2107; M17= Matrouh 2017/2108; N16= Nubaria 2016/2017; N17= Nubaria 2017/2018; W16= Al-Wadi Al-Asiouty 2016/2017; W17= Al-Wadi Al-Asiouty 2017/2018) for mean grain yield/plant (g) using genotypic and environmental scores.

\section{AMMI2 biplot}

The AMMI2 biplot illustrated the relationship between IPCA1 and IPCA2 (Fig. 2); which can be utilized to interpret the extent of interaction between both genotypes and environments. The discriminative environments can be identified using the vector length in the AMMI biplot. According to the comparisons among environments using the vector length, the best discriminative environments were N16 and N17 followed by M16 and M17 as they showed the longest vectors midst all investigated environments. Furthermore, we found that the rest of environments exhibited shorter vectors length, which designated that they were not discriminative environments for the investigated genotypes. We detected acute angles between the vectors of environments, which indicated that they were positively interacted, e.g. N16 and N17, M16 and M17 and A17, W16 and W17. While obtuse angles among environments represented they were negatively interacted, e.g. N16 and M17, N17 and A16.

\section{Eberhart and Russell's stability analysis}

We visualized the relationship between variance of deviation from regression $\left(\mathrm{S}_{\mathrm{di}}^{2}\right)$ and coefficient of regression $\left(b_{i}\right)$ in order to identify adaptable DHs (Fig. 3). The DHs that showed smallest values of $\mathrm{S}_{\mathrm{di}}^{2}$ along with values of $b_{i}$ more than 1.0 were adapted DHs across environments (shown in red color). This included 122 adapted DHs, e.g. 293, 241, 25, 294, 186, 188, 20, 72, 266 and 116. Based on the aforementioned criteria of both $\mathrm{S}_{\mathrm{di}}^{2}$ and $b_{i}$ values, the local check or the two parents lacked adaptability across the eight investigated environments (Supplemental Table 1) 


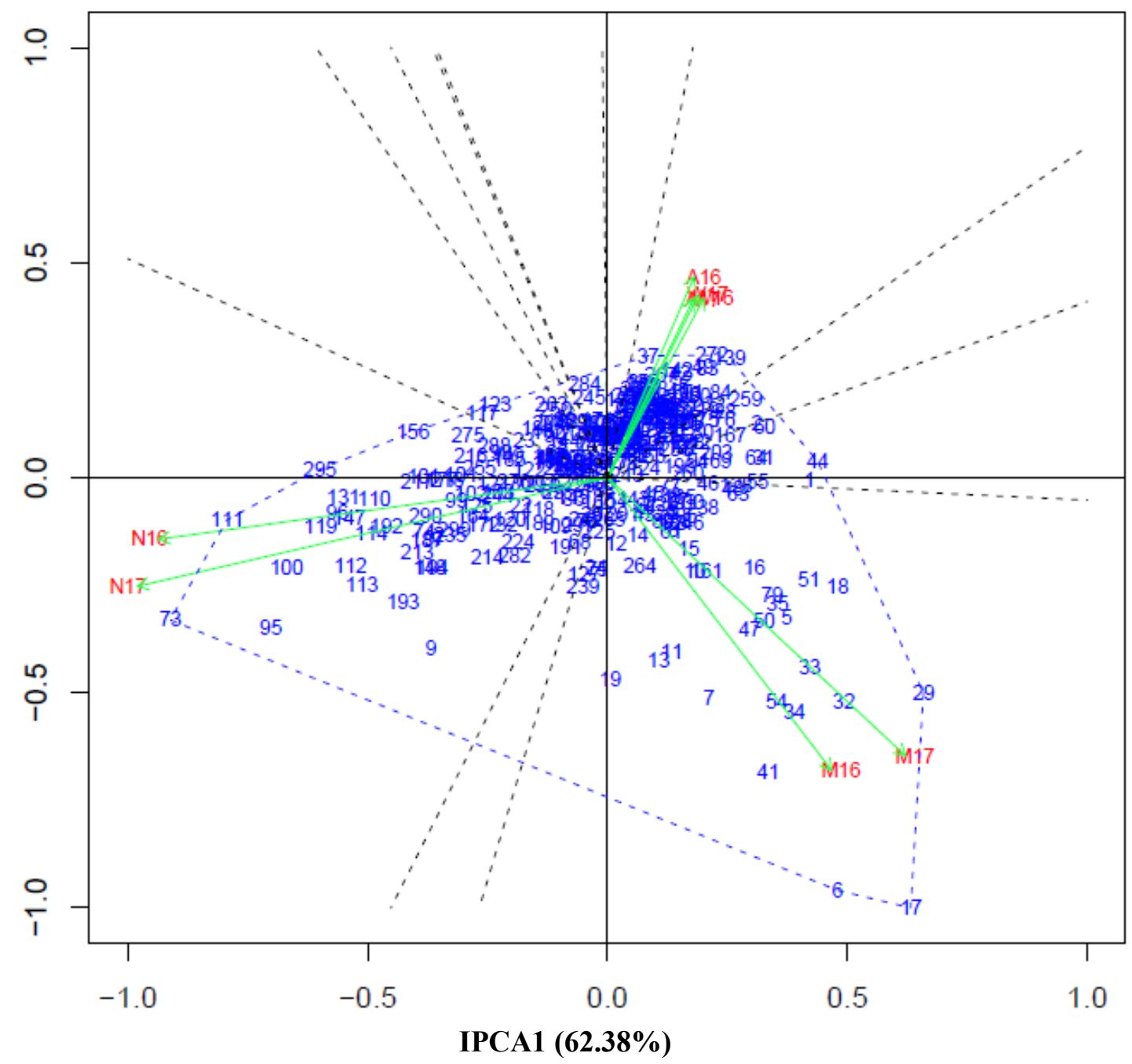

Fig. 2. Biplot of the second interaction principal component axis (IPCA2) against the first interaction principal component axis (IPCA1) scores for grain yield/plant (GYP; g) of a doubled haploid population of barley in eight environments (A16= Assiut 2016/2017; A17 = Assiut 2017/2018; M16= Matrouh 2016/2107; M17= Matrouh 2017/2108; N16= Nubaria 2016/2017; N17= Nubaria 2017/2018; W16= Al-Wadi Al-Asiouty 2016/2017; W17= Al-Wadi Al-Asiouty 2017/2018).

In order to identify DHs that shows good performance and stability, we visualize the relationship between average grain yield per plant for each line across the eight investigated environments and their coefficients of variation (CV \%) (Fig. 4). We found a reasonable number of DHs that showed good performance and were stable across the eight environments (shown in red color). These DHs possessed the highest mean of grain yield per plant across environments and the lowest CV\%. This included $43 \mathrm{DHs}$ that possessed a mean of GYP more than $5.5 \mathrm{~g}$ and a $\mathrm{CV} \%$ of less than $57 \%$, e.g. $15,87,27,124$, 159, 293, 241 and 26 (Supplemental Table 1).
In addition, the local check cultivar (Giza127) showed good performance and stability across environments. Moreover, both parents of the double haploid population yielded poorly less than the average mean yield per plant and was not stable across environments.

We detected $14 \mathrm{DHs}$ that were adapted based on the aforementioned criterion of both $\mathrm{S}^{2}{ }_{\mathrm{di}}$ and $b_{i}$ and showed good performance and stability based on both mean of GYP and CV\%. These DHs included, e.g. 293, 241, 160, 265 and 68 (Supplemental Table 1). 


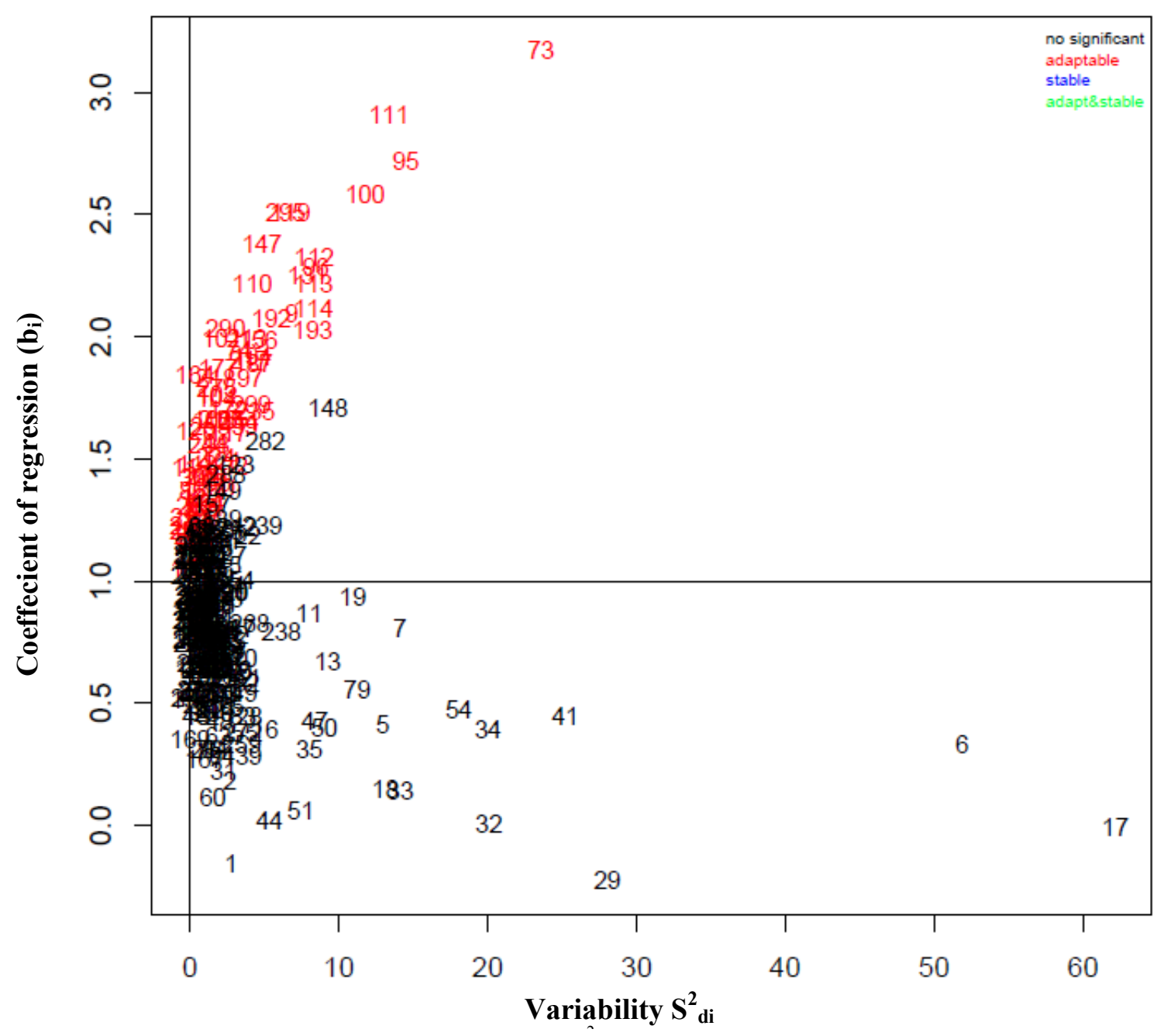

Fig. 3. Variability of variance of deviation of regression $\left(\mathrm{S}^{2}{ }_{\mathrm{di}}\right)$ plotted against coefficient of regression $\left(\mathrm{b}_{\mathrm{i}}\right)$ for grain yield/plant $(g)$ of the doubled haploid population of barley genotypes across eight environments.

Tai's stability analysis

Tai (1971) stability model partitions the $\mathrm{G} \times \mathrm{E}$ effect in to two constituents: $\alpha$ that measures the linear response to environmental effects and $\lambda$ that measures deviation from the linear response in terms of amount of the error variance. The distribution of the DHs on Alpha-Lambda space presenting different stability areas was showed in Fig. 5. The horizontal axis presents $\lambda$ and the vertical axis presents $\alpha$. The curve is prediction limits for $\alpha=0$ at significance level of 0.05 . The area between the $\alpha$ axis and $\lambda=1$, inside the curve with values of $\alpha$ not significantly different from 0 and $\lambda$ values non-significant different from 1 , includes average stable DHs and those with $\alpha<$ 0 and $\lambda=1$ represents above average stable DHs.
Therefore, DHLs that are located within the area above $\alpha=0$ and $\lambda=1$, i.e., $(\alpha>0, \lambda=1)$ would be considered as below average performance. Thus, there were 2 average stable DHs that showed values of $\alpha$ not significantly different from 0 and $\lambda$ values non-significant different from 1 and were located in the area between $\alpha$ axis and $\lambda=1$. These DHs included 266 and 188 . Moreover, we found three above stable DHs that were located in the area included $\alpha<0$ and $\lambda=1$. These above average DHs included 169, 137 and 278. Furthermore, the DHs that located within the area comprised $\alpha>0$ and $\lambda=1$ were considered as below average performance. This included 8 DHs (293, 241, 25, 294, 186, 20, 72 and 166) (Supplemental Table 1). 


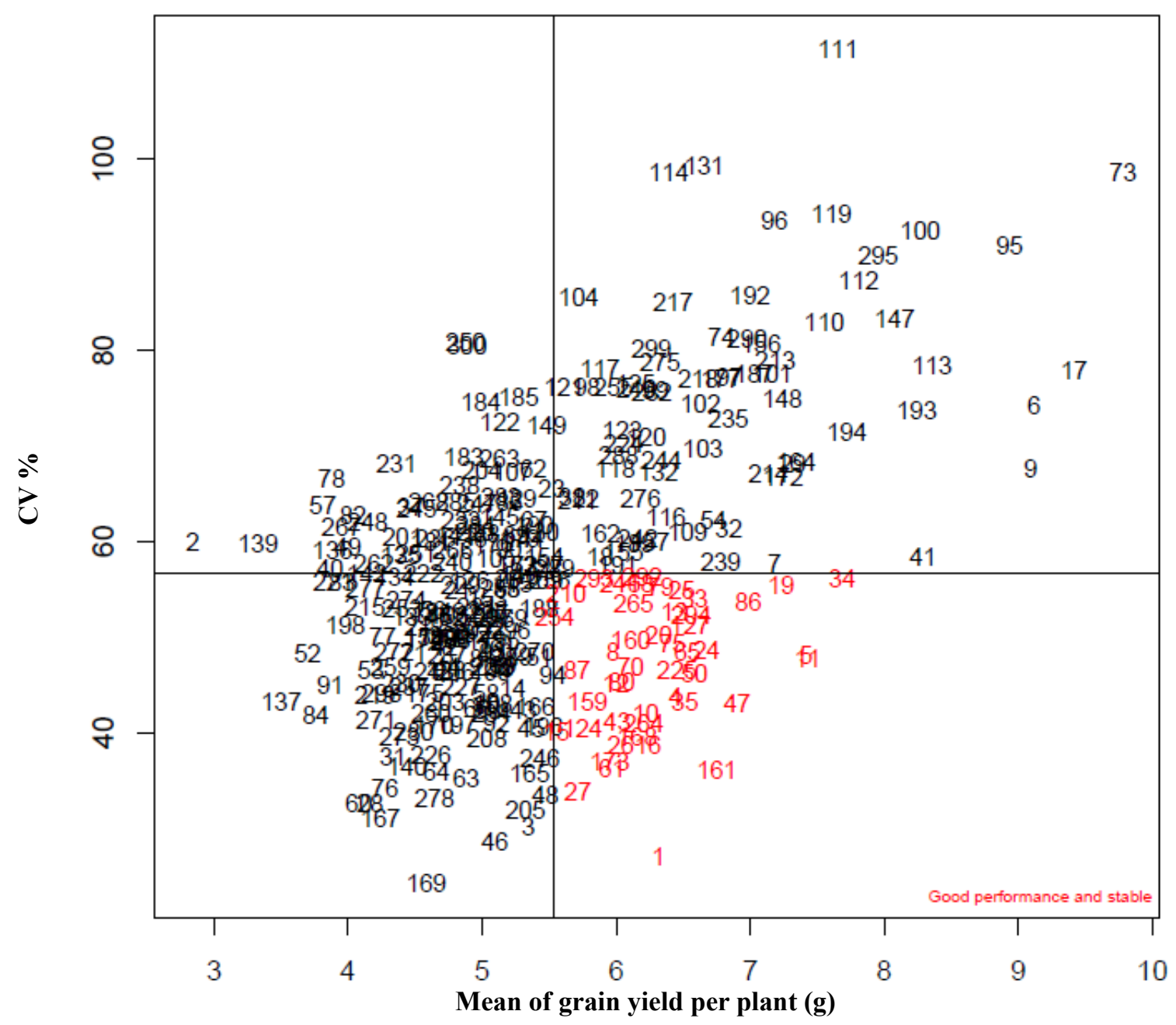

Fig 4. Mean of grain yield/plant plotted against CV (\%) from data collected on the doubled haploid population of barley in eight environments.

A perfectly stable $\mathrm{DH}$ is the one, which exposed an environmental effect $(\alpha)$ of -1 and a deviation from the linear response $(\lambda)$ of +1 . However, none of the tested DHs, in the current study, exhibited $\alpha$ value of -1 . This indicated that none of them was able to demonstrate a perfect/ static performance stability. Consequently, it could be presumed that genotypic performances across the eight environments were not consistent.

\section{Discussion}

We investigated stability parameters using eight environments, which was recommended by Annicchiarico (2002) and Gauch (2013) for reliable estimates of the stability parameters.

The first sole axis of the AMMI analysis possesses the highest proportion of the model (Gauch, 1988). This was consistent with our results as we found that the IPCA1 explained

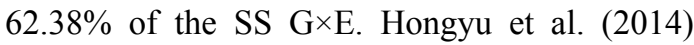
found that IPCA1 explained $\approx 56 \%$ of the $\mathrm{SS} \mathrm{G} \times \mathrm{E}$; in addition, they considered the rest of IPCAs as noise. Therefore, they suggested that the AMMAI1 was the paramount constituent to depict the $\mathrm{G} \times \mathrm{E}$. Moreover, about $87 \%$ of the $\mathrm{SS} \mathrm{G} \times \mathrm{E}$ is attributed to the first two IPCAs. In this regard, our results were harmonious with those found by Hongyu et al. (2014) who detected that the first two IPCAs were responsible for more than $70 \%$ of the SS $\mathrm{G} \times \mathrm{E}$. As indicated in the results section, we found that AMMI is an efficient statistical procedure, which can be employed to distinguish preferable environments and outstanding genotypes. In this context, our results were in harmony with those found by Gauch et al. (2008) and Yan (2010). 


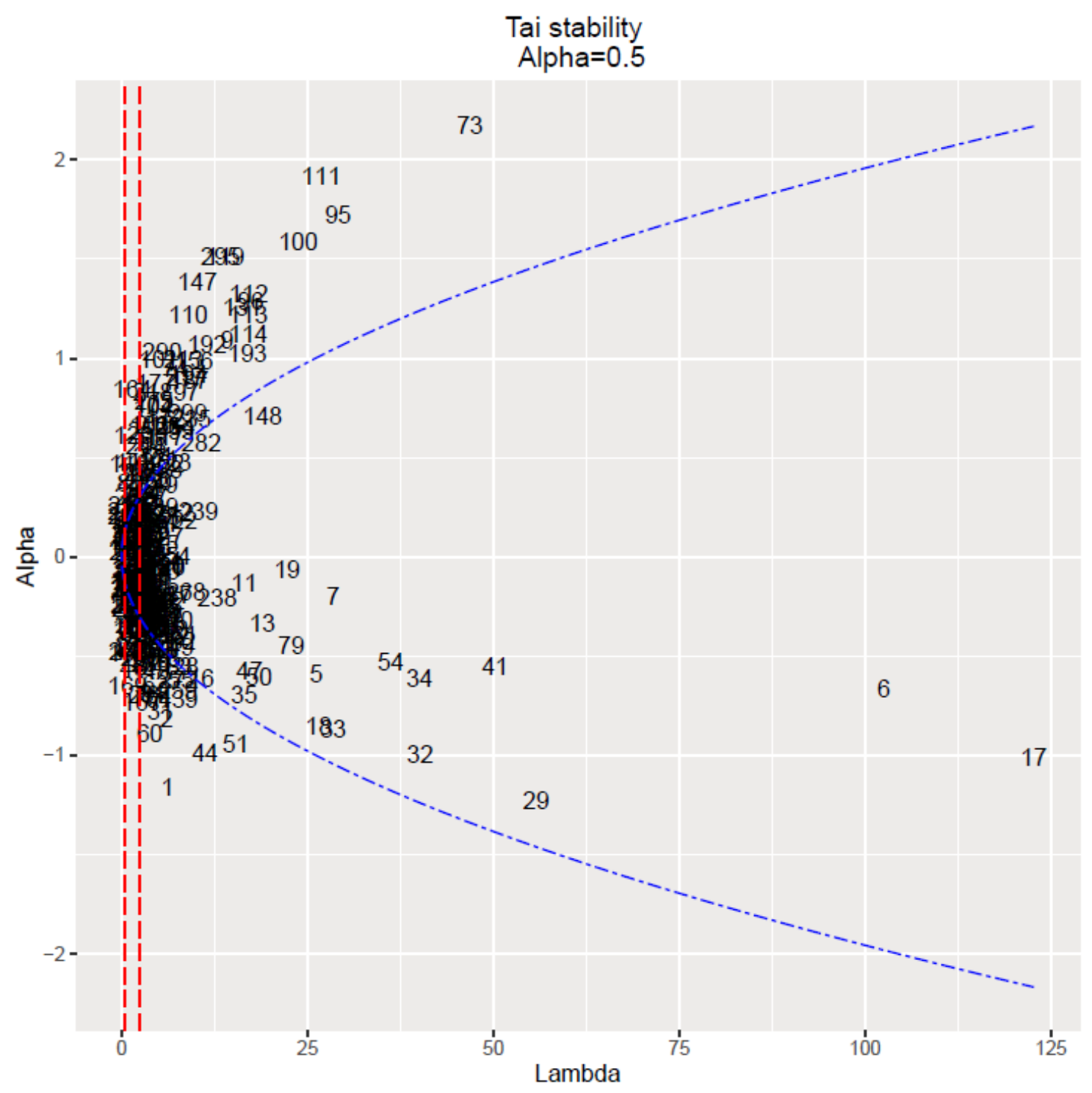

Fig. 5. Distribution of the DHs along with the check cultivar on Alpha-Lambda space showing different stability regions according to Tai (1971) method.

Johnson et al. (1955) categorized the broadsense heritability as the following: Low $\mathrm{h}_{\mathrm{b}}^{2}$ $(0-30 \%)$, medium $\mathrm{h}_{\mathrm{b}}^{2} \quad(31-60 \%)$ and high $\mathrm{h}_{\mathrm{b}}^{2} \quad(>61 \%)$. Furthermore, Robinson (1966) depended in magnitude for his classification as the following: low $h_{b}^{2}(<50 \%)$, moderate $h_{b}^{2}(50-$ $70 \%)$ and high $\mathrm{h}_{\mathrm{b}}^{2}(>70 \%)$. However, we suggest a slightly modified classification using four categories as the following: Low $\mathrm{h}_{\mathrm{b}}^{2}(0-25 \%)$, moderate $(26-50 \%)$, highly moderate $(51-75 \%)$ and high (76-100\%). Therefore, according to our classification of heritability, broad-sense heritability was moderate for grain yield per plant (50\%).

Sivasubramanian \& Menon (1973) suggested that when PCV and GCV \% are less than $10 \%$; they are classified as low values, if they are ranged between $10-20 \%$; they are considered as moderate values and lastly, if they show values more than $20 \%$; then they are categorized as high values. Therefore, according to PCV\%, GYP was considered as high value as it exceeded $20 \%$. On the other hand, based on the 
GCV\%, GYP was considered as moderate value $(14.47 \%)$. Unche et al. (2008) indicated that high PCV and GCV\% for traits of interest can be elucidated the high potential of these traits to be improved via breeding programs unlike low PCV and GCV\%. This indicate that GYP, in our study, possess the potential of improvement.

We used Eberhart and Russell's stability analysis as a type of parametric stability measure of stability. Many studies used this analysis to identify stable genotypes in barley including Khalili \& Pour-Aboughadareh (2016) and Kumar et al. (2016). We found 14 DHs that showed good performance and stability across environments.

Some studies (Asfaw et al., 2009; Alwala et al., 2010 and Rad et al., 2013) exhibited similar results using either joint regression model of Eberhart and Russell or AMMI biplot analysis. On the other hand, Flores et al. (1998) indicated that might fail to identify stable genotypes due to violation of certain assumption as well as using large number of genotypes. However, Miranda et al. (2009) emphasized the consistency of both AMMI biplot analysis and Eberhart and Russell to assess $\mathrm{G} \times \mathrm{E}$ using reasonable number of genotypes.

According to Tai's stability analysis, we identified three categories of DHs, in terms of stability, including above average, average and below average. However, none of the DHs showed perfect/static performance stability. Therefore, we presume that the performance of DHs was not consistent across environments. Our results of Tai's stability analysis were consistent with those found by Attia et al. (2007) and Tolessa (2015).

\section{Conclusion}

The differences in identifying stable DHs, in our study, might be attributed to using large number of genotypes, which might be not convenient to certain stability models such as those of Tai and Eberhart and Russell. Both Eberhart and Tai models were able to detect stable DHs across environments; however, only AMMI model possessed the ability to categorize the DHs based on which-won-where pattern. In addition, based on the moderate broad-sense heritability estimates, we found that grain yield per plant might be improved under the investigated environments. In addition, some of the DHs were stable and exceeded the performance of the parents as well as the local check cultivar. Therefore, we highly recommend using these promising DHs, to develop varieties. Furthermore, some DHs performed well in certain environments, which might be used to release varieties targeted to such environments.

Acknowledgments: The authors wish to thank colleagues at Ecology and Dry Land Agriculture Division, Desert Research Center, El-Matarya, Cairo, for hosting Matrouh location and colleagues at Field Crops Department, National Research Centre, Cairo, for hosting Nubariah location. The help of Prof. Dr. Jens Léon, University of Bonn, Germany is duly acknowledged for providing the S42 doubled haploid population of barley.

\section{$\underline{\text { References }}$}

Addisu, A. and Shumet, T. (2015) Variability, heritability and genetic advance for some yield and yield related traits in barley (Hordeum vulgare L.) landraces in Ethiopia. International Journal of Plant Breeding and Genetics, 9(2), 68-76.

Alvarado, G., López, M., Vargas, M., Pacheco, Á., Rodríguez, F., Burgueño, J. and Crossa, J. (2015) META-R (Multi Environment Trail Analysis with $\mathrm{R}$ for Windows. Version 5.0. CIMMYT.

Alwala, S., Kwolek, T., McPherson, M., Pellow, J. and Meyer, D. (2010) A comprehensive comparison between Eberhart and Russell joint regression and GGE biplot analyses to identify stable and high yielding maize hybrids. Field Crop Res. 119, 225 230.

Annicchiarico, P. (2002) Genotype $\times$ environment interaction: Challenges and opportunities for plant breeding and cultivar recommendations. Food and Agriculture Organization of the United Nations. FAO, Rome, Italy.

Arulbalachandran, D., Mullainathan, L., Velu, S. and Thilagavathi, C. (2010) Genetic variability, heritability and genetic advance of quantitative traits in black gram by effects of mutation in field trail. African Journal of Biotechnology, 9(19), 2731-2735.

Asfaw, A., Alemayehu, F., Gurum, F. and Atnaf, M. 
(2009) AMMI and SREG GGE biplot analysis for matching varieties onto soybean production environments in Ethiopia. Sci. Res and Ess. 4,13221330.

Attia, S.M., El-Hady, M.M., El-Taweel, A.M.S.A. and El-Harty, E.H. (2007) Stability statistics of some faba bean genotypes. Annals of Agric. Sc. Moshtohor, 45(2), 525-544.

Burton, G.W. and Devane, E.H. (1953) Estimating heritability in tall fescue (Festuca arundinacea) from replicated clonal material 1. Agronomy Journal, 45(10), 478-481.

Eberhart, S.A. and Russell, W.A. (1966) Stability parameters for comparing varieties. Crop Sci. 6, 36-40.

Flores, F., Moreno, M.T. and Cubero, J.I. (1998) A comparison of univariate and multivariate methods to analyze G $\times \mathrm{E}$ interaction. Field Crop Res. 56, 271-286.

Gauch, H.G. (1988) Model selection and validation for yield trials with interaction. Biometrics 44(3), 705-715.

Gauch, H.G. (1992) "Statistical Analysis of Regional Yield Trials: AMMI Analysis of Factorial Designs". Elsevier, Amsterdam.

Gauch, H.G. (2013) A simple protocol for AMMI analysis of yield trials. Crop Science, 53(5), 18601869.

Gauch, H.G., Piepho, H.P. and Annicchiarico, P. (2008) Statistical analysis of yield trials by AMMI and GGE: Further considerations. Crop Sci., 48, 866-889.

Gollob, H.F. (1968) A statistical model which combines features of factor analytic and analysis of variance techniques. Psychometrika, 33(1), 73115.

Hongyu, K., García-Peña, M., de Araújo, L.B. and dos Santos Dias, C.T. (2014) Statistical analysis of yield trials by AMMI analysis of genotype $\times$ environment interaction. Biometrical Letters, 51(2), 89-102.

Johnson, H.W., Robinson, H.F. and Comstock, R. (1955) Estimates of genetic and environmental variability in soybeans 1. Agronomy Journal, 47(7), 314-318.

Kang, M.S. and Pham H.N. (1991) Simultaneous selection for high yielding and stable crop $\mathrm{G}$. Agron. J. 83, 161-165.

Khalili, M. and Pour-Aboughadareh, A. (2016) Parametric and non-parametric measures for evaluating yield stability and adaptability in barley doubled haploid lines. Journal of Agricultural Science and Technology, 18(3), 789-803.

Kumar, V., Kharub, A.S., Verma, R.P.S. and Verma, A. (2016) AMMI, GGE biplots and regression analysis to comprehend the $\mathrm{G} \times \mathrm{E}$ interaction in multi-environment barley trials. Indian Journal of Genet. 76, 202-204.

Miranda, G.V., Souza, L.V.D., Guimarães, L.J.M., Namorato, H., Oliveira, L.R. and Soares, M.O. (2009) Multivariate analyses of genotype $\mathrm{x}$ environment interaction of popcorn. Pesquisa Agropecuária Brasileira, 44(1), 45-50.

Pacheco, A., Vargas, M., Alvarado, G., Rodríguez, F., López, M., Crossa, J. and Burgueño, J. (2016) GEA-R (Genotype $\times$ Environment Analysis whit $\mathrm{R}$ for Windows.) Version 4.0, http://hdl. handle. net/11529/10203 International Maize and Wheat Improvement Center.

Rad, M.N., Kadir, M.A., Rafii, M.Y., Jaafar, H.Z., Naghavi, M.R. and Ahmadi, F. (2013) Genotype $\times$ environment interaction by AMMI and GGE biplot analysis in three consecutive generations of wheat (Triticum aestivum) under normal and drought stress conditions. Aust. J. Crop Sci. 7, 956-961.

Robinson, H.F. (1966) Quantitative genetics in relation to breeding of the centennial of mendalism. Indian J Genet. 26, 171-187.

Sivasubramanian, S. and Menon, M. (1973) Heterosis and inbreeding depression in rice. Madras Agric. J. 60, 1139.

Tai, G.C. (1971) Genotypic stability analysis and its application to potato regional trials. Crop Science, 11(2), 184-190.

Tolessa, T.T. (2015) Application of AMMI and Tai's stability statistics for yield stability analysis in faba bean (Vicia faba L.) cultivars grown in Central 
Highlands of Ethiopia. Journal of Plant Sciences, 3(4), 197-206

Unche, P.B., Misal, M.B., Borgaonkar, S.B., Godhawale, G.V., Chavan, B.D. and Sawant, D.R. (2008) Genetic variability studies in sweet sorghum (Sorghum bicolor L. Moench). Int. J. Plant Sci. 3(1), 16-18.

von Bothmer, R., Sato, K., Komatsuda, T., Yasuda, S. and Fischbeck, G. (2003) In: "Diversity in Barley", von Bothmer, R., van Hintum, T., Knuepffer, H., Sato, K. (Ed), pp. 9-27. Elsevier, Amsterdam.

von Korff, M., Wang, H., Léon, J. and Pillen, K. (2004)

Development of candidate introgression lines using an exotic barley accession (H. vulgare ssp. spontaneum). as donor. Theoretical and Applied Genetics, 109(8), 1736-1745.

Yan, W. (2010) Optimal use of biplots in analysis of multi-location variety test data. Acta Agronomica Sinica, 36(11), 1805-1819.

Zobel, R.W., Wright, M.J. and Gauch, H.G. (1988) Statistical analysis of a yield trial. Agron. J. 80, 388-393.

(Received 8/10/2018; accepted $17 / 2 / 2019)$

\section{تحليلات الثبات ودرجة التوريث في عشيرة من الثعير متضاعفة العدد الصبغي الأحادي \\ محمد بدري محمد علي، محمد عبد العزيز عبدالحليم سيد الميد

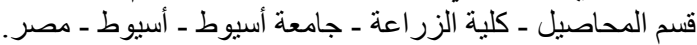

لُعد تقييم التفاعل البيئي الور اثي خطوة مهمة في أي برنامج تربية من خلال التجارب متعددة المو اقع. في هذه

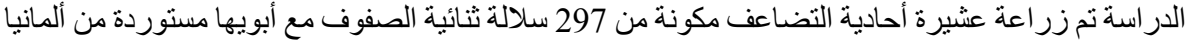

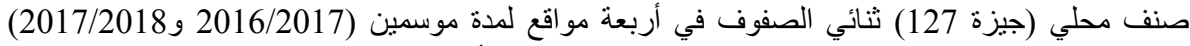

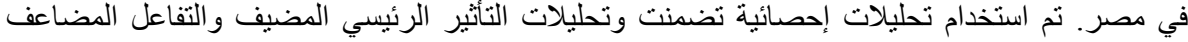

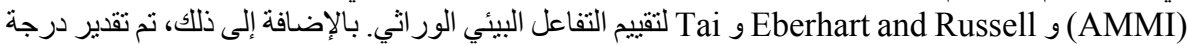

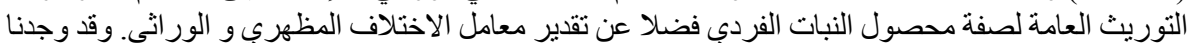

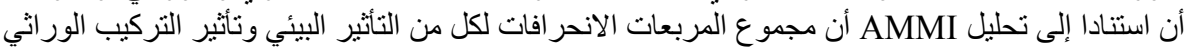

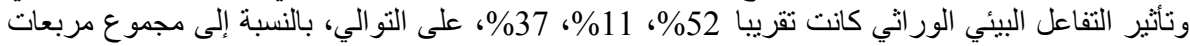

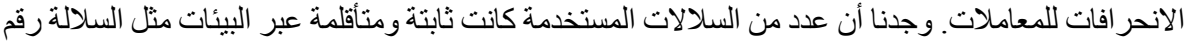

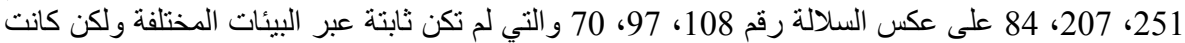

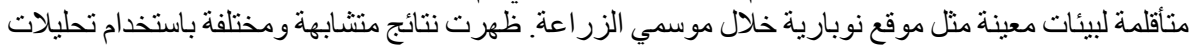

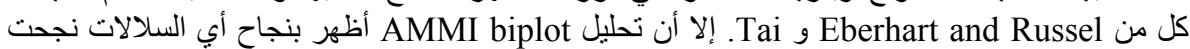

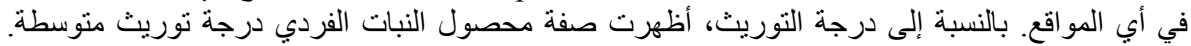

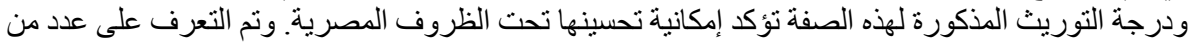

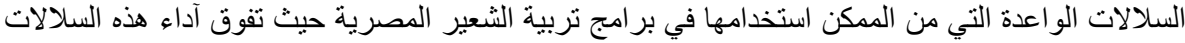
على أبويهاو الصنف المحلي. 